\title{
A Proposed Standard of Stability for Passenger Ships.
}

\section{(Part II : Small Crafts)}

\author{
By Mitsuo Sato, \\ Yasubumi Yamanouchi, \\ Seizo Motora, \\ and Mamoru Uchida,
}

\author{
Kogakushi, Member, \\ Kogakushi, Member, \\ Kogakushi, Member \\ Kogakushi, Member.
}

\section{\$1. Introduction}

Small crafts of less than 5 gross were outside the scope of "Ship Safety Law," but even such crafts intended to carry passengers have become subject to the application of the Law by its Amendment made in July, last year. A standard of stability for these crafts has been prepared accordingly and is now in force in the form of "Small Crafts Safety Ragulations."

This standard was worked out in a similar manner as that for Smooth Water Area*, that is by the Ministry of Transportation with cooperation of Tokyo and Kyushu Universities, and Nippon Kaiji Kyokai (Japan Marine Corporation).

Notations used in this paper are shown in Table 1, unless expressly defined elsewhere.

TABLE 1.

\begin{tabular}{|c|c|c|c|}
\hline \multirow[t]{2}{*}{$\begin{array}{l}\text { Boat } \\
\text { Boat }\end{array}$} & \multirow{2}{*}{$\begin{array}{c}L \\
B \\
D\end{array}$} & & $\begin{array}{c}\text { No. of } \\
\text { passengers } \\
0 \quad n\end{array}$ \\
\hline & & Draft, above $K$, in $m$ & $d$ \\
\hline Average weight of a person, in ton & $w$ & Freeboard, in $m$ & $f_{0}$ \\
\hline Number of passengers & $n$ & , in ton & $\Delta_{0}$ \\
\hline $\begin{array}{l}\text { Athwartship distance, within which } \\
\text { passengers may move, in } m\end{array}$ & $\bar{B}$ & $\begin{array}{l}\text { Volume displacement, in } m^{3} \\
\text { Waterplane area, in } m^{2}\end{array}$ & $\begin{array}{ll}V_{0} & V \\
A_{w 0} & A_{w}\end{array}$ \\
\hline $\begin{array}{l}\text { Area of passenger space, in } m^{2} \\
\text { Total area of passenger spaces, in } m^{2}\end{array}$ & $A_{t}$ & $\begin{array}{l}\text { Moment of inertia of waterplane } \\
\text { area, in } m^{4}\end{array}$ & $\begin{array}{ll}\Lambda_{w 0} & \lambda_{w} \\
I_{0} & I\end{array}$ \\
\hline $\begin{array}{l}\text { Height of top of passenger floor, } \\
\text { above } K \text {, in } m\end{array}$ & $\begin{array}{l}A \\
h_{i}\end{array}$ & $\begin{array}{l}\text { Block coefficient } \\
\text { Waterplane area coefficient }\end{array}$ & $\begin{array}{ll}C_{b 0} & C_{b} \\
C_{w 0} & C_{w}\end{array}$ \\
\hline $\begin{array}{l}\text { Average height of tops of passenger } \\
\text { floors above } \mathrm{K} \text {, in } m\end{array}$ & $h$ & Center of gravity & $\mathrm{G}_{0}$ \\
\hline Shifting weight, in ton & $W$ & Center of buoyancy. & $\mathrm{B}_{0}$ \\
\hline $\begin{array}{l}\text { Distance of movement of shifting } \\
\text { weight, in } m\end{array}$ & $h$ & $\begin{array}{l}\text { Transverse metacenter } \\
\text { Top of keel }\end{array}$ & $\mathrm{M}_{\mathrm{K}} \mathrm{M}$ \\
\hline Length of pendulum, in $m$ & $l$ & Specific gravity of water & $\sigma$ \\
\hline Defle & $s$ & & \\
\hline
\end{tabular}

\section{§ 2. Basic Principles}

It was decided to adapt and simplify the standard for vessels in the Smooth Water Area, and thus to follow the same basic principles with the following modifications:-

(1) Stability of a small craft must be determined in terms of $L, B, D$ and $d_{0}$ or $f_{0}$ as the exact form or displacement of such a craft may not be readily available in most cases. Incidental inac=

* A Proposed Standard of Stability for Passenger Ships-Part I: Smooth Water Area. Journal Soc. Nav. Arch. Japan, Vol. 95 
curacy of a certain degree must be tolerated.

(2) $\Delta_{0} \cdot \mathrm{G}_{0} \mathrm{M}_{0}\left(\equiv S_{0}\right.$ ) will be determined by means of inclining experiment, and thence $\Delta \cdot \mathrm{GM}$ estimated from data on existing crafts.

(3) Steady wind of $10 \mathrm{~m} / \mathrm{sec}$ strength can incline small crafts only as little as about 2 degrees. Therefore, heeling moment due to movement of passengers to be considered.

(4) Maximum permissible inclination, or side immersion, will be limited, with a certain allow ance for wind pressure, to $70 \%$ of available freeboard.

\section{$\S 3 . \quad \Delta \cdot G M$ when carrying Passengers}

When $\Delta_{0} \cdot \mathrm{G}_{0} \mathrm{M}_{0}$ is known, $\Delta \cdot \mathrm{GM}$ can be estimated by the following formula :

$$
\mathrm{GM} \fallingdotseq \mathrm{KB}+\mathrm{BM}-\mathrm{KG} \quad \text { therefore, } \quad \Delta \cdot \mathrm{GM}=\Delta \cdot \mathrm{KB}+\Delta \cdot \mathrm{BM}-\Delta \cdot \mathrm{KG}
$$

where

$$
\mathrm{KB}=d-\frac{1}{3}\left(\frac{1}{2} d+\frac{V}{A_{w}}\right)=\frac{5}{6} d-\frac{1}{3} \frac{\Delta}{\sigma A_{w}} \text { and } \mathrm{BM}=\frac{I}{V}=\frac{\sigma I}{\Delta}
$$

Assuming that the center of gravity of passengers is located $1.00 \mathrm{~m}$ above the top of floor,

$$
\mathrm{KG}=\left\{\Delta_{0} \cdot \mathrm{KG}_{0}+w n(h+1)\right\} / \Delta
$$

Thence,

$$
\Delta \cdot \mathrm{GM}=\frac{5}{6} \Delta d-\frac{1}{3} \frac{\Delta^{2}}{\sigma A_{w}}+\sigma I-\Delta_{0} \mathrm{KG}_{0}-w n(h+1)
$$

and

$$
\Delta_{0} \cdot \mathrm{G}_{0} \mathrm{M}_{0}=\frac{5}{6} \Delta_{0} d_{0}-\frac{1}{3} \frac{\Delta_{0}^{2}}{\sigma A_{w 0}}+\sigma I_{0}-\Delta_{0} \cdot \mathrm{KG}_{0}
$$

Therefore

$$
\Delta_{0} \cdot \mathrm{G}_{0} \mathrm{M}_{0}-\Delta \cdot \mathrm{GM}=\frac{5}{6}\left(\Delta_{0} d_{0}-\Delta d\right)-\frac{1}{3 \sigma}\left(\frac{\Delta_{0}{ }^{2}}{A_{w 0}}-\frac{\Delta^{2}}{A_{w}}\right)+\sigma\left(I_{0}-I\right)+w n(h+1)
$$

By substituting,

$$
\begin{array}{llll}
\Delta=\Delta_{0}+w n & d \doteqdot d_{0}+\frac{2 w n}{\sigma\left(A_{w 0}+A_{w}\right)} & A_{w 0}=L B C_{w 0} & A_{w}=L B C_{w} \\
I_{0}=k_{0} L B^{3} & I=k L B^{3} & \Delta_{0}=\sigma L B d_{0} C_{\iota 0} & C_{w}=r C_{w 0}
\end{array}
$$

The above formula can be written :

$$
\begin{gathered}
\Delta_{0} \cdot \mathrm{G}_{0} \mathrm{M}_{0}-\Delta \cdot \mathrm{GM}=-\frac{4 r-1}{3 r(1+r) \sigma L B} C_{w 0}-(w n)^{2}+\left\{(h+1)-\frac{5}{6} d_{0}-\frac{(3 r-2) d_{0} C_{b 0}}{3 r(1+r) C_{w 0}}\right\}(w n) \\
-\frac{(r-1) \sigma L B d_{0}^{2} C_{b 0}^{2}}{3 r C_{\omega 0}}-\sigma\left(k-k_{0}\right) L B^{3}
\end{gathered}
$$

By dividing this by. $L B d_{0}{ }^{2}$, and writing $\Delta_{0} \cdot \mathrm{G}_{0} \mathrm{M}_{0} \equiv S_{0}$ and also assuming $\sigma \doteqdot 1$, we have :

$$
\begin{aligned}
\frac{S_{0}-\Delta \cdot G M}{L B d_{0}^{2}}= & -\frac{4 r-1}{3 r(1+r) C_{w 0}}\left(\frac{w n}{L B d_{0}}\right)^{2}+\left\{\frac{h+1}{d_{0}}-\frac{5}{6}-\frac{(3 r-2) C_{b 0}}{3 r(1+r) C_{w 0}}\right\} \frac{w n}{L B d_{0}} \\
& -\frac{(r-1) C^{2}{ }^{2}}{3 r C_{w 0}}-\left(k-k_{0}\right)\left(\begin{array}{c}
B \\
d_{0}
\end{array}\right)^{2}
\end{aligned}
$$

Hence, $\left(S_{0}-\Delta \cdot \mathrm{GM}\right) / L B d_{0}^{2}$ appears to be dependent mainly on $n / L B d_{0}$ and $(h+1) / d_{0}$. The change in $\Delta \cdot \mathrm{GM}$ due to change in $h$ may be determined, when, for instance, $\Delta \cdot \mathrm{G}_{1} \mathrm{M}$ at $h_{1}$ is known, by the formubla :

$$
\begin{gathered}
\Delta \cdot \mathrm{GM}-\Delta \cdot \mathrm{G}_{1} \mathrm{M}=-w n\left\{(h+1)-\left(h_{1}+1\right)\right\} \\
=-w n d_{0}\left(\frac{h+1}{d_{0} \cdot}-\frac{h_{1}+1}{d_{0}}\right) \quad \text { (1) }
\end{gathered}
$$

Thus, assuming a certain value of $(h$ $+1) / d_{0}\left[=\left(h_{1}+1\right) / d_{0} \equiv p\right]$, and when the actual values of $S_{0}, \Delta, \mathrm{G}_{1} \mathrm{M}$, etc. are determined from available ship data, and curve of $\left(S_{0}-\Delta \cdot G_{1} M\right) / L B d_{0}^{2}$ plotted on the basis of $n / L B d_{0}$, then $\left(S_{0}-\Delta \times\right.$

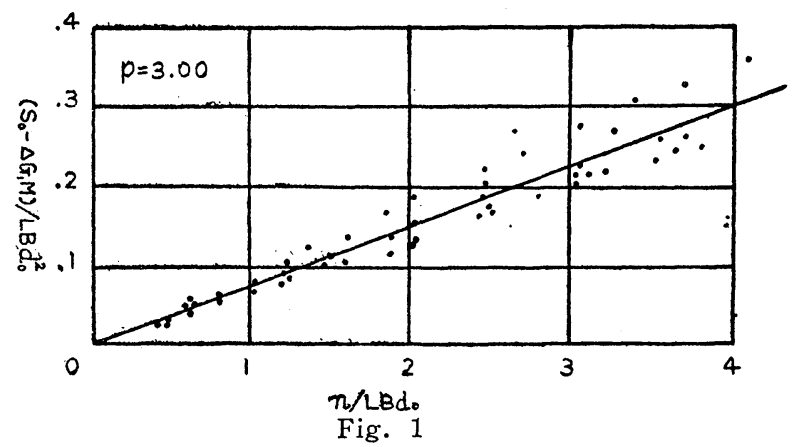


$\mathrm{GM}) / L B d_{0}^{2}$ of an, given ship corresponding to an arbitrary value of $(h+1) / d_{0}$ may be approximately estimated. Fig. 1 illustrates such a curve plotted from actual ship data with $p=3.00$. ( $S_{0}$ $\left.-\Delta \cdot G_{1} \mathrm{M}\right) / L B d_{0}{ }^{2}$ may be regarded to vary linearly with $n / L B d_{0}$. When, for instance, writing ( $S_{0}$ $\left.-\Delta \cdot \mathrm{G}_{1} \mathrm{M}\right) / L B d_{0}{ }^{2}=a w n / L B d_{0}$ for $\left(h_{1}+1\right) / d_{0}=p$,

$$
S_{0}-\Delta \cdot \mathrm{G}_{1} \mathrm{M}=a w n d_{0}
$$

Introducing into this equation allowance for change in $h$,

$$
S_{0}-\Delta \cdot \mathrm{GM}=a w n d_{0}+w n d_{0}\left(\frac{h+1}{d_{0}}-p\right)=w n\left\{h+1-(p-a) d_{0}\right\}
$$

From Fig. $1, p=3.00$ and $a=1.25$, and also taking $w=0.06$ (ton),

$$
S_{0}-\Delta \cdot \mathrm{GM}=0.06 n\left(h+1-1.75 d_{0}\right)
$$

\section{$\S 4 . \quad \Delta_{0} \cdot G_{0} M_{0}$ when carrying no Passengers}

$\Delta_{0} \cdot \mathrm{G}_{0} \mathrm{M}_{0}$, or $S_{0}$, could be determined by inclining experiment of the craft at standby condition without passengers, and from the formula:

$$
S_{0}=W \cdot b / \frac{s}{l}
$$

So thus obtained, however, will not give real $S_{0}$ on account of the effects of shifting weights and measurers on board during the experiment. In order to minimize the error, the test must be made without the crew aboard, and also the total weight of shifting weights and measurers should be less than that of (No. of crew +2 ) men. This is practicable with small crafts, for which shifting weight of $60 \mathrm{~kg}$ on each side is sufficient to carry out the experiment.

To obtain the real $S_{j}$, complete with crew on board, correction must be made for weight of the order of (No. of crew +2$)-N o$. of crew $=2$ persons and for its position. But such correction may be omitted and formula (4) used as it is, because it is on the safe side, and also because of small difference between experimental $S_{0}$ and real $S_{0}\left(\equiv S_{0}{ }^{\prime}\right)$, as shown on Table 2 .

\section{$\S 5$. Inclination due to Shift of Passengers and its Limit}

If the inclination of a ship due to shift of passengers is limited to an angle $\theta$,

$$
\Delta \cdot \mathrm{GM} \geq c \cdot w n \bar{B} / \tan \theta \text {, or } S_{0} \geq S_{0}-\Delta \cdot \mathrm{GM}+\frac{c w n \bar{B}}{\tan \theta}
$$

The results of calculations with the various ships indicate :

$$
\bar{B} \fallingdotseq 0: 9 B
$$

Where, taking the density of passengers before and after the shift, similar to the previous case of Smooth Water Area, as 3.33 and 7.00 persons $/ m^{2}$ respectively,

$$
c=\frac{1}{4}\left(1-\frac{3.33}{7}\right)=0.131
$$

If the maximum inclination or side immersion, is limited to that in the case of Smooth Water Area plus a certain allowance for wind pressure, i.e. to $70 \%$ of freeboard,

$$
\tan \theta=2(0.7 f) / B=1.4 f / B
$$

Also introducing $w=0.06$ (ton) into equation (5)

$$
S_{0} \geqq\left(S_{0}-\Delta \cdot G M\right)+\frac{0.01 n B^{2}}{2 f}
$$

Where, limiting $f$ to the depth of side immersion at $20^{\circ}$ angle of heel, similar to the previous case

$$
f \leqq \frac{1}{2} B \tan 20^{\circ} \quad \text { or } \quad f \leqq B / 5.5
$$

Next, $f$ may be estimated by

$$
f \doteqdot f_{0}-\frac{2 w n}{\sigma\left(C_{w 0}+C_{w}\right) L B}
$$


Where, $\frac{1}{2}\left(C_{w 0}+C_{w}\right) \doteqdot 0.7$ for ordinary small crafts, and taking $\sigma \doteqdot 1$ and $w=0.06$ (ton),

$$
f=f_{0}-\frac{0.085 n}{L B}
$$

On Table 3 are shown $f$-values of ships, of which data are known, calculated from formula ( 8$)$ in comparison with $f\left(\equiv f^{\prime}\right)$ values obtained from their hydrostatic curves. It may be said that formula $(8)$ is acceptable for practical use.

TABLE 2

\begin{tabular}{c|c|c}
\hline Ships & $\begin{array}{c}S_{0} \\
\text { (ton }-m)\end{array}$ & $\begin{array}{c}S_{0^{\prime}} \\
\text { (ton }-m)\end{array}$ \\
\hline K 1 & 1.98 & 2.03 \\
K 2 & 2.61 & 2.67 \\
K 3 & 2.16 & 2.19 \\
K 4 & 6.71 & 6.78 \\
K 5 & 5.59 & 5.66 \\
K 6 & 4.62 & 4.70 \\
K 7 & 5.72 & 5.73 \\
K 8 & 8.85 & 8.88 \\
\hline
\end{tabular}

TABLE 3

\begin{tabular}{c|c|c}
\hline Ships & $f(m)$ & $f^{\prime}(m)$ \\
\hline K 1 & 0.55 & 0.55 \\
K 2 & 0.75 & 0.75 \\
K 3 & 0.57 & 0.57 \\
K 4 & 0.68 & 0.68 \\
K 5 & 0.83 & 0.84 \\
K 6 & 0.77 & 0.77 \\
K 7 & 0.45 & 0.46 \\
K 8 & 0.64 & 0.66 \\
\hline
\end{tabular}

\section{$\S 6$. Standard of Stability}

Standard of stability may be written, from equations (2) and (5), as

$$
S_{0} \geqq w n\left\{1+h-(p-a) d_{0}+\frac{c \cdot \bar{B}}{\tan \theta}\right\}
$$

To transform this formula into a practical one, substitute equations (3), (6), (7) and (8), ar.d we have

$$
S_{0} \geqq \frac{n}{100}\left(6+6 h-10.5 d_{0}+\frac{B^{2}}{2 f}\right), \quad f=f_{0}-\frac{0.085 n}{L B} \leqq \begin{gathered}
B \\
5.5
\end{gathered}
$$

Whereas, Article 16 of Small Crafts Safety Regulations provides that area of passenger space be not less than $0.25 \mathrm{~m}^{2}$ per person, $n\left(\equiv n_{A}\right)$ may be determined from available area for passengers, and substituted into formula (10) to check the stability. In practice, however, it is more convenient to find $n$ ( $\equiv n_{S}$ ) from formula (10) at first, then compare it with $n_{A}$, and determine the capacity of passengers. For this purpose, the next method is recommended to simplify the calculation, which may be otherwise complicated, as the formula (10) is a quadratic equation of variable $n$. First, substitute $n$ in equation ( 8 ) with $n_{A}=A / 0: 25$, and from equation ( 7 ), we have

$$
f=f_{0}-\frac{0.34 A}{L B} \leqq \frac{B}{5.5}
$$

Therefore, the solution is to use this $f$-value for $f$ in equation (10), determine $n\left(\equiv n_{S}\right)$, and compare the result with $n_{A}$. When, however, $n_{S}$ is found less than $n_{A}$, and $f_{0}-0.34 A / L B$ also less than $B / 5.5$, it will give too rigorous a result, since a freeboard with $n_{A}$ number of passengers, more than $n_{S}$, has been used to obtain $n_{S}$, In this case, equation ( 8 ) must be used.

To sum up the foregoing discussions, the standard of stability for small crafts and its calculation procedure may be numerated as follows :

(1.) Inclining experiment to be made at the condition without passenger and crew but with fuel, water, equipment and outfit aboard at their normal position. But the total weight of shifting weights and measurers should not exceed $0.06 \mathrm{x}$ (No. of crew +2$)$ tons.

$$
S_{0}=W \cdot b / \frac{s}{l}
$$


TABLE 4

\begin{tabular}{|c|c|c|c|c|c|c|c|}
\hline Shipś & $L(m)$ & $\times B(m)$ & $\times d_{0}(m)$ & $\begin{array}{c}S_{0} \\
\text { (ton-m) }\end{array}$ & $n_{\Lambda}$ & $n_{S}$ & $n_{S^{\prime}}$ \\
\hline K 1 & 7.50 & $\times 2.30$ & $\times 0.40$ & 1.98 & 30 & $\hat{\sim} 20$ & - \\
\hline K 2 & 7.80 & $\times 2.50$ & $\times 0.42$ & 2.61 & 乞21 & $\xi 21$ & - \\
\hline K 3 & 8.50 & $\times 2.30$ & $\times 0.50$ & 2.16 & 度19 & 23 & - \\
\hline K 4 & 11.00 & $\times 2.58$ & $\times 0.27$ & 6.71 & 乞27 & 51 & - \\
\hline K 5 & 11.00 & $\times 2.64$ & $\times 0.56$ & 5.59 & 52 & $\sum 51$ & - \\
\hline K 6 & 11.00 & $\times 2.70$ & $\times 0.41$ & 4.62 & 41 & 约37 & - \\
\hline K 7 & 11.20 & $\times 2.65$ & $\times 0.66$ & 5.72 & $\sum 37$ & 49 & - \\
\hline K 8 & 11.38 & $\times 2.97$ & $\times 0.73$ & 8.85 & 乞556 & 59 & - \\
\hline K 9 & 7.00 & $\times 2.10$ & $\times 0.50$ & 1.30 & 24 & 红11 & $\{11$ \\
\hline K 10 & 12.38 & $\times 2.83$ & $\times 0.40$ & 7.83 & 乏.59 & 63 & - \\
\hline K 11 & 7.53 & $\times 1.69$ & $\times 0.28$ & 0.94 & 18 & $\sum 10$ & - \\
\hline K 12 & 7.75 & $\times 1.88$ & $\times 0.26$ & 1.71 & 20 & 公18 & - \\
\hline K 13 & 8.55 & $\times 2.10$ & $\times 0.26$ & 2.73 & 27 & $\sum 25$ & - \\
\hline K 14 & 8.95 & $\times 2.04$ & $\times 0.21$ & 2.09 & 34 & 18 & 定19 \\
\hline K 15 & 6.40 & $\times 1.86$ & $\times 0.24$ & 2.26 & $\sum 14$ & 23 & - \\
\hline $\mathrm{K} 16$ & 5.58 & $\times 1.75$ & $\begin{array}{r}\times 0.33 \\
\end{array}$ & 0.70 & 11 & $\approx 8$ & - \\
\hline K 17 & 12.35 & $\times 2.87$ & $\times 0.23$ & 7.45 & 66 & $\sum 52$ & - \\
\hline K 18 & 9.70 & $\times 2.04$ & $\times 0.20$ & 2.33 & 40 & 31 & 乞t32 \\
\hline K 19 & 12.77 & $\times 2.57$ & $\times 0.22$ & 6.38 & $\sum 74$ & 83 & - \\
\hline K 20 & $8.60^{\circ}$ & $\times 16.2$ & $\times 0.35$ & 1.80 & $\hat{\Sigma} 15$ & 20 & - \\
\hline K 21 & 8.85 & $\begin{array}{r}\times 1.98 \\
\end{array}$ & $\times 0.22$ & 1.45 & 35 & 12 & 棺13 \\
\hline K 22 & 7.42 & $\times 2.02$ & $\times 0.27$ & 1.60 & 岤13 & 16 & - \\
\hline K 23 & 10.00 & $\times 2.59$ & $\times 0.34$ & 4.83 & 它29 & 43 & - \\
\hline K 24 & 7.90 & $\times 2.47$ & $\times 0.51$ & 2.38 & 27 & 它22 & - \\
\hline K 25 & 10.25 & $\times 2.18$ & $\times 0.49$ & 7.88 & $\sum 32$ & 88 & - \\
\hline K 26 & 10.20 & $\times 2.37$ & $\times 0.22$ & 3.25 & 公15 & 27 & 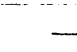 \\
\hline K 27 & 11.50 & $\times 2.68$ & $\times 0.21$ & 5.74 & 53 & 定46 & - \\
\hline K 28 & 8.40 & $\times 2.35$ & $\times 0.47$ & 3.21 & 30 & $\sum 27$ & - \\
\hline K 29 & 7.25 & $\times 2.06$ & $\times 0.38$ & 1.38 & 26 & 柁12 & - \\
\hline K 30 & 9.30 & $\times 1.95$ & $\times 0.29$ & 2.28 & 25 & $\Sigma 22$ & - \\
\hline
\end{tabular}

Note : $i$ shows $n$ to be adopted.

(2) Determine maximum No. of passengers allowable by area of passenger space.

$$
n_{A}=A / 0.25=\sum A_{i} / 0.25
$$

(3) Find maximum No. of passengers allowable by stability point of view.

(Predetermine $h$ from $h=\sum A_{i} h_{i} / \sum A_{i}$ )

$$
n_{S} \leqq \frac{100 S_{0}}{6+6 h-10.5 d_{0}+\frac{B^{2}}{2 f}}, \quad f=f_{0}-\frac{0.34 A}{L B} \leqq \frac{B}{5.5}
$$

$n_{S}$ or $n_{A}$, whichever the less, is adopted as the maximum $n$ allowable, except in the next case (4). (4) When $n_{S}$ is less than $n_{A}$, and $f_{0}-0.34 A / L B$ also less than $B_{l} / 5.5$, the next $n_{S}{ }^{\prime}$ gives the $n$ to be assigned.

$$
n_{S} \leqq \frac{100 S_{0}}{6+6 h-10.5 d_{0}+\frac{B^{2}}{2 f}}, \quad f=f_{0}-\frac{0.085 n_{S^{\prime}}}{L B} \leqq \frac{B}{5.5}
$$


on Table 4 are shown some of the results of calculation on actual ships.

\section{$\S 7$. Review}

(1) For small crafts, their stability must be determined with limited informations available, and consequently inaccuracy of a certain degree cannot be avoided. There are involved (a) adoption of mean line in Fig. 1, (b) neglect of effects of shifting weights as inclining experiment, and (c) uniform assumption of 0.7 for any $\frac{1}{2}\left(C_{w}+C_{w 0}\right)$. Combined errors of these simplifying measures are shown in Table 5 , where $F$ is $70 \%$ of the freeboard with $n$ passengers (calculated by the proposed method) or $70 \%$ of $\frac{1}{2} B \tan 20^{\circ}$, whichever the less, and $F^{\prime}$ is the depth of side im mersion when inclined by a heeling moment of $c w n$. $\bar{B}$. These values were obtained from detailed calculations on ships for which complete data were available. In effect, our method shows the ship to incline as much as $F$, while the ship actually inclines as much as $F^{\prime}$.

TABLE 5

\begin{tabular}{c|c|c}
\hline Ships & $F(m)$ & $F^{\prime}(m)$ \\
\hline K 1 & 0.29 & 0.27 \\
K 2 & 0.32 & 0.30 \\
K 3 & 0.29 & 0.29 \\
K 4 & 0.32 & 0.22 \\
K 5 & 0.34 & 0.38 \\
K 6 & 0.34 & 0.20 \\
K 7 & 0.32 & 0.30 \\
K 8 & 0.38 & 0.34 \\
\hline
\end{tabular}

TABLE 6

\begin{tabular}{c|c|c}
\hline Ships & $F(m)$ & $F^{\prime \prime}(m)$ \\
\hline K 11 & 0.22 & 0.21 \\
K 16 & 0.23 & 0.28 \\
K 21 & 0.25 & 0.31 \\
K 22 & 0.26 & 0.28 \\
\hline
\end{tabular}

(2) In order to assure the practicability of this standard, the authors conducted passenger-shifting experiments on actual ships at Tokyo Port and Kawaguchi and Yamanaka Lakes, and their results are shown on Table 6. where, $F$ is $70 \%$ of the freeboard with $n_{S}$ passengers aboard, or $70 \%$ of $\frac{1}{2} B \tan$ $20^{\circ}$, whichever the less, and $F^{\prime \prime}$ is the loss of freeboard due to inclination effected by shift of $n_{S}$ passengers. Both values were obtained from direct measurement. The table shows in effect that the ship should incline as much as $F$ according to our method, but it did incline as much as $F^{\prime \prime}$ in fact.

(3) As demonstrated above. the proposed standard may be deemed efficiently practicable at present, but when more informations are gathered to construct Fig. I for each type of ship, and more realistic values of $-\frac{1}{2}\left(C_{w}+C_{w 0}\right)$ determined, higher accuracy maybe obtained in the future.

\section{§ 8. Conclusions}

The authors have attempted to describe the principles and procedures in preparing the proposed standard and are pleased to note in conclusion :

(1) that the standard of stability has been selected as such that will give sufficient initial stability to the ship against normally feasible shift of passengers, and

(2) that the method of determining ship's stability only by its length, breadth, stability without passengers, draft and such has been developed. Finally, it is the authors' sincerest wish that many a weak points in this standard will be remedied and more reasonable standard developed in the future.

('Translated by Kazuyo Nakayama, Member) 